\title{
Une administration ouest-allemande en charge des œuvres d'art à restituer après le nazisme : la Treuhandverwaltung für Kulturgut (1952-1962)
}

\section{Marie-Bénédicte Vincent}

\section{(2) OpenEdition}

\section{Journals}

Édition électronique

URL : http://journals.openedition.org/ifha/8072

DOI : $10.4000 /$ ifha. 8072

ISSN : 2198-8943

\section{Éditeur}

IFRA - Institut franco-allemand (sciences historiques et sociales)

\section{Édition imprimée}

Date de publication : 31 décembre 2014

ISSN : 2190-0078

\section{Référence électronique}

Marie-Bénédicte Vincent, « Une administration ouest-allemande en charge des œuvres d'art à restituer après le nazisme : la Treuhandverwaltung für Kulturgut (1952-1962)", Revue de l'IFHA [En ligne], 6 | 2014, mis en ligne le 31 décembre 2014, consulté le 21 avril 2019. URL : http://journals.openedition.org/ ifha/8072 ; DOl : 10.4000/ifha.8072

Ce document a été généré automatiquement le 21 avril 2019

(CIFHA 


\title{
Une administration ouest- allemande en charge des œuvres d'art à restituer après le nazisme : la Treuhandverwaltung für Kulturgut (1952-1962)
}

\author{
Marie-Bénédicte Vincent
}

\section{Une institution au croisement des influences}

La Treuhandverwaltung für Kulturgut (TVK) est une administration créée en République fédérale d'Allemagne (RFA) en 1952, chargée de la conservation des œuvres d'art qui, après avoir été pillées ou spoliées par les nazis entre 1933 et 1945, ont été récupérées par les Alliés occidentaux à la fin de la Seconde Guerre mondiale. Le sujet du pillage et des restitutions d'œuvres d'art en Europe après 1945 est aujourd'hui très à la mode dans l'historiographie, d'autant qu'il s'agit d'une histoire inachevée. De nombreux ouvrages collectifs ont vu le jour depuis les années 2000, tant en Allemagne qu'aux États-Unis ${ }^{1}$. La plupart se concentrent soit sur les œuvres et leur provenance (ce qui est compréhensible, car certaines étaient d'une valeur artistique et financière inestimable), soit sur la politique générale de restitution des Alliés occidentaux - les Soviétiques n'ayant pas restitué les biens qu'ils avaient saisis - et sur les récupérations effectuées par les différents pays ayant subi l'occupation allemande. Mais finalement, nous ne disposons que de très peu d'informations sur les acteurs ouest-allemands ayant mis en œuvre cette politique $^{2}$, notamment sur l'administration en charge de la conservation et de la préparation des restitutions qu'est la TVK ${ }^{3}$. Dans son livre récent consacré au traitement médiatique des retours d'œuvres d'art en France entre 1945 et 20084, Corinne Bouchoux évoque en quelques pages la TVK, tout en soulignant l'absence d'un bilan critique de son action. Cet article ambitionne d'approcher au plus près cette administration par la 
consultation de ses archives ${ }^{5}$ et l'étude de son personnel, qui œuvre à la charnière des champs diplomatique, administratif et artistique.

C'est dans une optique d'histoire sociale que nous abordons la TVK, la question étant de savoir comment son personnel est recruté, quel est son passé avant 1945 et quelles sont les raisons qui le rendent crédible face aux instances ouest-allemandes mais aussi face aux Occidentaux. Ce faisant, cette recherche rejoint le vaste chantier sur les continuités personnelles dans les ministères de la RFA depuis 1945 et le degré de compromission des grands acteurs et décideurs de l'après-guerre. En particulier, le livre collectif Das Amt und die Vergangenheit ${ }^{6}$, qui a eu une large réception en Allemagne, intéresse de près cette recherche puisque la TVK dépendait hiérarchiquement du ministère des Affaires étrangères. Il importe de savoir comment les administrations ouest-allemandes ont été reconstruites après la phase épuratoire initiale, c'est-à-dire en tenant compte des réintégrations rapides (dès les premières années après la guerre) et massives de personnel ayant un passé "brun $»^{7}$, et quelles en sont les conséquences en termes de pratiques administratives. Dans un livre récent, Dominik Rigoll évoque la concurrence au sein des services publics ouest-allemands entre les hommes nouveaux promus en 1945 ( die 1945er) et la masse des « anciens » ayant bénéficié des généreuses lois d'amnistie et de réhabilitation (die 1947er) ${ }^{8}$. Il apparaît dès lors judicieux d'entreprendre des enquêtes fines sur les personnels pour entrer dans le fonctionnement des administrations. La TVK s'avère être un bon observatoire, car il s'agit d'une petite structure au plan des effectifs, mais située au cœur de grands enjeux, parmi lesquels la définition d'une politique étrangère ouest-allemande qui se veut de plus en plus autonome face aux Alliés - l' Auswärtiges Amt est créé en 1951 avec Adenauer comme ministre des Affaires étrangères jusqu'en 1955 -, la nécessité pour la RFA de restituer les œuvres d'art pour s'intégrer au camp occidental (ce thème s'insérant plus largement dans sa politique du passé ou Vergangenheitsbewältigung), mais aussi la réflexion sur le patrimoine culturel, qui sort de la sphère strictement administrative en impliquant experts et historiens d'art et touche l'opinion via les débats parlementaires ou la presse, avec une charge émotive forte lors du déplacement d'œuvres à l'étranger.

3 Nous situerons en premier lieu la position intermédiaire de la TVK entre les contraintes exercées par les Alliés, les velléités d'autonomie de la RFA et les pressions de la société civile ouest-allemande. Puis, nous nous pencherons sur le personnel de la TVK en nous intéressant entre autres à son dirigeant, le Dr Bernhard Hoffmann. Enfin, nous évoquerons la réflexion menée sur les biens culturels en RFA après la guerre à travers le travail de restitution préparé par la TVK.

\section{a) Une administration ouest-allemande en position d'intermédiaire}

4 De par sa mission de préparation des restitutions d'œuvres d'art tant en Allemagne de l'Ouest qu'à l'étranger, le travail de la TVK intéresse plusieurs groupes d'acteurs aux intérêts différents. La TVK doit d'abord tenir compte des exigences des puissances d'occupation, principalement des Américains puisqu'elle est située à Munich, dans l'ancienne zone américaine. En l'absence d'une politique commune interalliée, pourtant prévue par le comité Mac Millan créé à Londres en avril 1944, les Américains ont donné le ton de la politique de restitution. Ils ont promulgué dans leur zone la loi militaire $\mathrm{n}^{\circ} 59 \mathrm{du}$ 10 novembre 1947, qui prévoit la restitution des biens saisis entre 1933 et 1945 pour des raisons raciales, idéologiques ou religieuses. Les lois correspondantes dans les zones 
française et britannique datent respectivement du 10 novembre 1947 (ordonnance $\mathrm{n}^{\circ} 120$ ) et du 12 mai 1949 (loi no 28) ${ }^{9}$. Côté allemand, ces lois sont perçues comme des sanctions et non comme une réparation juste pour les actes commis sous le nazisme. Après 1949, les Alliés continuent de contrôler la politique étrangère de la RFA en vertu du statut d'occupation : jusqu'à l'entrée en vigueur de l'Überleitungsvertrag en 1955, la décision des restitutions incombe aux hauts commissaires alliés. En même temps, la TVK participe de la reconstruction des administrations ouest-allemandes, car elle est placée sous le contrôle du Land de Bavière, puis du Bund. Enfin, les enjeux soulevés suscitent l'intérêt des experts de la société civile, qui tentent de défendre des points de vue différents de ceux des Alliés et veulent contrôler la pertinence des réclamations émanant des pays ayant subi le joug nazi.

\section{b) Des œuvres placées sous la tutelle de la Bavière}

5 Jusqu'en août 1948, les Américains conservent les œuvres d'art saisies par leurs troupes en 1945 dans quatre Collecting Points à Munich, Wiesbaden, Marbach et Offenbach (il n'est pas nécessaire de revenir ici sur la gigantesque chasse au trésor menée par les Monuments Men jusqu'aux multiples caches nazies à la fin de la guerre ${ }^{10}$ ). Le principal dépôt à Munich, ouvert début juin 1945, a vu transiter plus d'un million d'objets. Dirigé par Craigh Hugh Smyth $^{11}$, il a employé dès le départ des Allemands de l'Ouest habilités par le commandement militaire, qui avait établi une « liste blanche » de personnes susceptibles de coopérer avec les Alliés (SHAEF White List of Art personnel) ${ }^{12}$. Rapidement, Munich est devenu le lieu principal de stockage (Central Collecting Point, CCP). Les restitutions ont commencé dès l'été 1945 (la première œuvre rendue le 26 août 1945 est le retable de L'Agneau mystique de Gand). Le CCP restitue environ 32000 objets entre août 1945 et décembre $1949^{13}$. Mais les propriétaires de nombreuses œuvres en dépôt restent non identifiées.

6 Le 23 août 1948, les Américains décident de transférer la tutelle (Treuhand) du CCP sur près de 10000 œuvres d'art au Land de Bavière. Cette tutelle est exercée par le Ministerpräsident, qui la confie au directeur des collections de peinture de l'État (Bayerische Staatsgemäldesammlungen) dépendant du Kultusministerium du Land, le Dr Eberhard Hanfstaengl. Hanfstaengl est un historien d'art qui, après une thèse en 1911 sur l'art médiéval, a commencé sa carrière en dirigeant à partir de 1925 les collections municipales de Munich de la Lehnbach Haus, avant d'être promu directeur de la Nationalgalerie à Berlin en janvier $1934^{14}$. Bien qu'il appartienne au milieu nationalconservateur, le Völkischer Beobachter fait son éloge à cette date, en mettant en avant sa capacité à promouvoir "l'art allemand » au détriment des modes contemporaines ${ }^{15}$. Les relations de Hanfstaengl avec les nazis se détériorent cependant par la suite : chargé d'organiser la délégation allemande de l'art contemporain à l'exposition internationale de Venise (Biennale), Hanfstaengl doit composer avec les artistes officiellement célébrés par le régime, tels le sculpteur Josef Wackerle et le peintre Oswald Poetzelberger, et donner satisfaction à Hitler, qui visite le pavillon allemand en juin 1934. Hanfstaengl est limogé en 1937, quand il refuse de retirer de la Nationalgalerie les toiles des artistes décrétés "dégénérés " conformément aux instructions de la Reichskammer der bildenden Künste dirigée par Adolf Ziegler. Hanfstaengl renoue après la guerre avec l'art moderne en organisant à Munich en 1947 une exposition sur la peinture française de l'impressionnisme au $\mathrm{XX}^{\mathrm{e}}$ siècle. Il retrouve ses fonctions de commissaire allemand à la 
Biennale de Venise de 1958 à 1968. De par son parcours, cet historien d'art est non seulement bien vu des Alliés occidentaux dans l'immédiat après-guerre, mais jouit d'une aura politique en RFA (il est qualifié « d'homme intègre » par Theodor Heuss en 1961).

7 Concrètement, la tutelle de la Bavière porte sur quatre types d'objets récupérés à la fin de la Seconde Guerre mondiale par les Américains: premièrement ceux destinés au Führermuseum de Linz, deuxièmement ceux émanant des collections privées de hauts dignitaires nazis (tel Göring), troisièmement ceux saisis par les nazis dans divers musées et collections, et quatrièmement ceux pris par les troupes américaines pour les mettre à l'abri des destructions. Certaines œuvres sont la propriété des anciens États de Prusse ou du Reich, d'autres du NSDAP. Initialement, la tutelle de la Bavière ne portait pas sur des œuvres appartenant à des particuliers allemands, mais cette catégorie a par la suite été incluse à la fermeture du CCP le 30 novembre 1949. Quant au Collecting Point de Wiesbaden, il conserve, jusqu'à sa clôture en août 1950, les œuvres saisies dans les dépôts nazis de la zone d'occupation américaine en Autriche (dont Alt-Aussee). Celles-ci sont ensuite transférées à Munich. L'annexe 1 récapitule les œuvres sous tutelle bavaroise en avril 1951 (selon un classement de la TVK).

\section{c) Le désir d'implication des experts ouest-allemands}

8 S'il est clair que les Alliés occidentaux conservent jusqu'en 1955 la compétence pour effectuer ou non des restitutions, certains experts ouest-allemands font montre de leur désir d'être associés à la procédure. Ainsi, le 20 avril 1949, la conférence des ministres des Länder en charge des affaires culturelles crée un "Comité allemand de restitution », qui veut être reconnu comme partenaire par les Alliés ${ }^{16}$. L'enjeu principal est de récupérer les archives du CCP (photos et inventaires des œuvres), qui servent lors des demandes de restitution : «Le danger existe de voir sinon ces documents conservés ailleurs et devenir inaccessibles pour les intérêts allemands » dit un rapport du Comité allemand le 22 juillet 1949. L'argument est que ces documents ne peuvent être confiés au Bureau de la Paix situé à Stuttgart (officine créée en avril 1947 par d'anciens résistants au nazisme et qui veut jouer le rôle d'un futur ministère des Affaires étrangères ${ }^{17}$ ), car il est dépourvu d'experts en histoire de l'art. Le Comité allemand de restitution débute ses travaux le 29 juin 1949 à Munich, sous la direction du Dr Sattler, secrétaire d'État au Kultusministerium de Bavière. Il se présente, dans un compte rendu du 8 janvier 1951, comme une instance consultative, voire décisionnelle, en matière de droit international (eine Stelle zur Beratung und Entscheidung der schwierigen völkerrechtlichen Fragen), afin de défendre les intérêts de la RFA (il ambitionne d'être une Verteidigerstelle) ${ }^{18}$. Clairement, le Comité souhaitait exercer un « contrôle» sur les restitutions, comme le dit le rapport final du 25 février $1952^{19}$.

Mais les autorités d'occupation américaines, en la personne de Stefan P. Munsing (1915-1994) de la Cultural Affairs Branch, refusent le 9 août 1949 de livrer les photocopies des archives du CCP au Comité. Notons qu'une demande parallèle de Rose Valland pour la France, ainsi que le projet français de créer un comité interzonal de restitution en octobre 1949, sont aussi rejetés par les Américains ${ }^{20}$. Le Comité allemand est tenté de se dissoudre, car il devient clair que la question doit se régler diplomatiquement. Début février 1950, le Comité demande au chancelier Konrad Adenauer une subvention et son patronage politique. Adenauer donne son accord en avril 1950 et informe les hauts commissaires alliés de sa volonté de créer un bureau fédéral (sans recevoir de réponse des Américains, car le contexte est alors celui de l'attente d'une révision du statut 
d'occupation de l'Allemagne). Adenauer prévoit néanmoins un financement de $20000 \mathrm{DM}$ par le bureau des Affaires extérieures de la chancellerie, embryon du ministère des Affaires étrangères (institué en mars 1951).

Revenons sur les experts du "Comité allemand" pour comprendre quels profils se dégagent: y siègent le Dr Ludwig Heydenreich, historien d'art du Zentralinstitut für Kunstgeschichte de Munich (il s'agit de l'institut fondé en mars 1947 sur proposition de Craigh Hugh Smyth pour travailler en coopération étroite avec les Américains du CCP et qui joue un rôle important dans la reconstitution d'un milieu culturel non nazi $\left.{ }^{21}\right)$, le professeur Dr Holzinger du Kultusministerium de Hesse à Wiesbaden, le professeur Dr comte Franz Wolff von Metternich (qui présidait le Conseil des musées dans la zone britannique), le professeur Dr. Kurt Martin (historien d'art en charge des musées et des expositions rhénans dans la zone française), et le Dr Erich Kaufmann (professeur de droit à l'Université de Munich). Ces personnalités disposent d'une légitimité politique les rendant acceptables par les Alliés. Ainsi, Heydenreich possède un profil d'antinazi. Des recherches nominatives dans le fichier de l'Amt Rosenberg du NSDAP chargé de la surveillance des intellectuels et artistes ${ }^{22}$ montre que ce spécialiste de la Renaissance italienne, en poste à l'Université de Berlin, passe dans un rapport du 15 mai 1940 pour "ami de juif», car il a été l'élève du professeur Erwin Panofsky à Hambourg: Heydenreich aurait favorisé l'obtention du doctorat à Hambourg d'un "demi-juif», raison pour laquelle il était mal vu des nazis, qui ne souhaitent pas l'impliquer dans leur programme de conférences d'éducation populaire malgré ses talents. Metternich est connu pour avoir joué pendant la guerre un rôle jugé positif par les résistants français tels Jacques Jaujard (Directeur des Musées nationaux) et Rose Valland (qui l'évoque dans ses mémoires $\left.{ }^{23}\right)$ : pendant l'Occupation, Metternich, en charge du service de la "protection artistique » (Kunstschutz) au sein de l'administration militaire à Paris, s'est opposé jusqu'à son remplacement au transfert sans autorisation militaire d'œuvres d'art vers l'Allemagne, entrant en conflit sur ce point avec l'ambassade allemande et l' Einsatzstab Reichsleiter Rosenberg (ERR) ${ }^{24}$. Quant à Kurt Martin, son rôle est évoqué de manière positive par Rose Valland, qui dit qu'il «s'était acquis pendant la guerre la reconnaissance des Strasbourgeois » et qu'il « [l']accompagna souvent dans les tournées d'inspection avec Jean Rigaud » en zone française ${ }^{25}$.

11 Le cas de Kaufmann est plus complexe: depuis l'entre-deux-guerres, il fait figure de juriste spécialisé dans la défense des intérêts allemands au niveau international. Des recherches nominatives dans les archives fédérales ${ }^{26}$ montrent qu'il a joué un rôle d'expert pour le ministère des Finances de la République de Weimar lors des négociations sur le plan Young en 1929, qui avait pour objet de réévaluer les réparations allemandes (Kaufmann se trouvait à Paris en août 1929 et envoyait des rapports à Berlin). En septembre 1949, il est de nouveau sollicité par Bonn pour émettre un avis sur la loi $\mathrm{n}^{\circ} 75$ du gouvernement militaire de l'Allemagne concernant la décartellisation ${ }^{27}$ : il pose alors la question de savoir si cette loi va au-delà des compétences des puissances d'occupation au regard du droit international et juge insuffisantes les compensations financières prévues pour dédommager les propriétaires lors des expropriations. Ce type d'experts, sollicité par les organisations économiques allemandes pour défendre les intérêts de la RFA, n'exerce certes pas une grande influence sur les gouvernements militaires alliés, mais est très écouté par les administrations ouest-allemandes. Au total, on voit dans l'implication des experts du Comité allemand de restitution un subtil dosage entre une 
légitimité politique antinazie nécessaire face aux Alliés et la défense des «intérêts allemands ".

\section{d) Le transfert de la tutelle au gouvernement fédéral}

12 Il faut attendre début 1951 pour voir le Comité allemand de restitution se doter d'un bureau permanent à Munich, où les premières réunions ont lieu le 8 janvier 1951 et le 19 février 1951. Le bureau est dirigé par le Dr Bernhard Hoffmann, un ancien employé allemand du CCP. Sa mission officielle est de compléter le fichier original du CCP élaboré jusqu'à 1948 (12000 fiches manuscrites sur les œuvres stockées), de contrôler la concordance des plus de 50000 photos avec ce fichier et de veiller à la bonne conservation des œuvres en attente de restitution. Dans un courrier adressé à Adenauer le 16 avril 1951, le haut commissaire américain Mc Clay prend acte de l'existence de ce bureau et se dit prêt à transférer à la RFA la tutelle des œuvres en attente de restitution ${ }^{28}$, ainsi que les fiches d'inventaires et les photos, étant entendu que les Alliés conservent toujours à cette date la compétence pour décider des restitutions. Adenauer accepte le principe le 27 juillet 1951 et c'est le 22 février 1952 qu'a lieu officiellement le transfert de la tutelle sur plus de 9200 œuvres d'art de la Bavière au Bund. Les activités du Comité allemand de restitution, qui estime avoir rempli son rôle, s'achèvent le 31 mars 1952. Entre juillet 1949 et février 1952, environ 1800 objets ont été restitués ${ }^{29}$.

Le bureau fédéral de la TVK, installé à Munich, est placé sous l'autorité hiérarchique d'un bureau (le Referat 605) du service culturel (Kulturabteilung) du ministère des Affaires étrangères à Bonn. Hoffmann, directeur de la TVK à Munich, devient contractuel du ministère (Angstellter des öffentlichen Dienstes auf Zeit), avec un salaire mensuel d'un peu plus de $650 \mathrm{DM}$ en $1953^{30}$. Quant au service du ministère à Bonn chargé de la TVK, il est initialement dirigé par le Dr Bernhard von Tieschowitz (historien d'art nommé en mars $1952^{31}$ ), l'ancien adjoint puis successeur de Metternich à partir de 1942 en France ${ }^{32}$, ce qui montre, côté ouest-allemand, le choix politique de s'appuyer sur des personnalités antinazies face aux puissances d'occupation. La TVK reçoit un budget conséquent d'un peu moins de 100000 DM annuels entre 1952 et 1960, qui s'élève à 110000 DM en 1961 puis 120000 DM en 1962. Le volume des œuvres sous tutelle fédérale s'est accru par l'inclusion des œuvres venant du Collecting Point de Wiesbaden, mais aussi d'objets ayant appartenu à des juifs en Allemagne ou en Tchécoslovaquie, Pologne et Russie. La tutelle porte aussi sur les œuvres venant de l'ancienne chancellerie du Reich. Mais de nombreux d'objets ne sont toujours pas identifiés en 1952. Nous reviendrons sur le travail d'iventorisation jusqu'à la dissolution de la TVK en 1962.

\section{Le personnel de la TVK : entre légitimité politique et expertise artistique}

La TVK de Munich est intéressante, car elle jouit d'une autonomie certaine face au ministère des Affaires étrangères, grâce d'une part à sa situation excentrée par rapport à Bonn et d'autre part au profil très particulier de son personnel sur lequel nous allons maintenant nous pencher. 


\section{a) Les critères de recrutement de la TVK}

15 Hoffmann insiste dans son rapport final de $1962^{33}$ sur les compétences universitaires en histoire de l'art du personnel qualifié de la TVK : « La conservation et le soin apportés aux œuvres sont une exigence non seulement matérielle au regard de leur importance, mais aussi éthique. L'affaire est exclusivement celle de personnes formées en histoire de l'art. » La TVK emploie, en dehors de Hoffmann, un autre docteur de l'université : le Dr Dorothea Westphal, qualifiée dans un document du 22 octobre 1952 écrit par von Tieschowitz "d'aide féminine excellente pour Hoffmann » sans être nommée (ce point montre sans doute la difficulté pour les diplomates de cette génération à reconnaître des cadres féminins). Westphal est née en 1902, possède une thèse en histoire de l'art (probablement sur l'art vénitien) et a travaillé avant la guerre comme assistante scientifique dans un musée à Berlin. Depuis 1951, elle est employée comme assistante scientifique par le Zentralinstitut de Munich pour traiter les questions relevant de l'histoire de l'art à la TVK. Elle semble insérée dans les réseaux universitaires internationaux - en 1955, elle est invitée à un congrès d'histoire de l'art à Venise - et parle italien. Elle dirige jusqu'en 1956 à la TVK le bureau des photographies (qui inventorie un fonds de 100000 clichés), avant d'être remplacée par Claire Roselius (qui a fréquenté la Kunstakademie de Munich de 1928 à 1931). Par ailleurs, Westphal est d'origine juive - elle est qualifiée d'ancienne «persécutée pour raisons raciales» dans une note ministérielle de 1957. Le profil de Westphal montre le choix assumé pour le recrutement du personnel d'une double légitimité politique et scientifique.

Ce double critère vaut aussi pour le choix des diplomates à Bonn ayant en charge la TVK. Au ministère des Affaires étrangères, le bureau de la TVK est confié, suite au départ de von Tieschowitz en 1953, à Werner von Beyme. Pour appuyer le recrutement de celui-ci, von Tieschowitz écrit le 5 septembre 1952 que ce fonctionnaire du Kultusministerium de Hesse, employé depuis 1947 dans le service du patrimoine et connaissant bien le Collecting Point de Wiesbaden - et donc les questions afférentes de restitution -, a fait ses études en histoire de l'art à Munich en 1934-1935 et achève une thèse dans cette discipline ${ }^{34}$. Il ajoute que Beyme est «non concerné par la loi de libération» de 1946 (qui instaure les procédures de dénazification), ce qui signifie qu'il n'est pas compromis dans le nazisme, et qu'issu de Posnanie, il jouit d'un statut de "réfugié de l'Est » : au total, il apparaît tout à fait "qualifié » pour prendre la direction du Referat à Bonn au printemps 1953 (entre octobre 1952 et avril 1953, c'est Hoffmann qui dirige par intérim le service ${ }^{35}$ ). En 1955, Hoffmann prend la succession de Beyme, cumulant ainsi la direction du bureau munichois et celle du service de Bonn. Examinons maintenant qui est ce personnage central de la TVK entre 1952 et 1962.

\section{b) Bernhard Hoffmann : un passeur entre plusieurs champs}

Même s'il n'est pas possible de consulter les Personalakten du Dr Bernhard Hoffmann, on dispose par recoupement de nombreuses informations sur lui. Né en 1920 à Erfurt, il est marié et installé à Munich (cet argument est utilisé dans les années 1950 pour justifier les dédommagements qu'il perçoit pour ses déplacements à Bonn). Mobilisé entre 1939 et 1943, il a le statut de mutilé de guerre. Auteur en 1948 d'une thèse en histoire de l'art, qui a obtenu la mention très bien, sa carrière a commencé au $\mathrm{CCP}$, où il a travaillé comme «curateur » pour les Américains à partir de janvier 1949. Puis il dirige jusqu'en 1951 le 
bureau de tutelle des œuvres d'art pour le compte de la Bavière. Depuis février 1951, il est employé par la direction des Collections de peintures de l'État de Bavière pour administrer la TVK. Parallèlement, il est choisi pour diriger le Comité allemand de restitution, ce qui lui donne une légitimité au niveau fédéral et un contact avec les experts des autres zones. Il apparaît dès lors polyvalent: connaisseur d'art, bon administrateur, mais aussi diplomate et accepté tant par les Américains que par les historiens d'art. Un rapport du ministère du 25 septembre 1954 le qualifie de «meilleur expert en Allemagne sur la question des restitutions $»^{36}$ et une autre note d'avril 1955 affirme qu'il est «l'unique personne à être la plus familière du dossier " ${ }^{37}$.

Or la question des restitutions fait partie des points à négocier avec les Alliés dans le futur traité de paix concernant l'Allemagne. C'est pour cette raison qu'Hoffmann est appelé à Bonn en 1955, année où la RFA redevient souveraine suite aux accords de Paris du 23 octobre 1954, afin de préparer le lien avec la nouvelle instance fédérale endossant, à la place des Alliés, la responsabilité des restitutions «extérieures »: il s'agit du Bundesamt für äussere Restitution, dépendant du ministère fédéral des Finances et situé à Bad Homburg, qui reçoit à partir du 5 mai 1955 les réclamations des pays étrangers. Hoffmann jouit alors du rang diplomatique de Legationsrat. En 1962, quand la TVK est dissoute, Hoffmann peine à retrouver un poste dans l'administration fédérale (le ministère des Affaires étrangères note le 23 mai 1962 qu'il n'y a pas de poste pour lui au ministère fédéral de l'Intérieur et évoque comme possibilité l'administration de la Bavière ${ }^{38}$ ) : il est sans doute réemployé dans l'administration du Land de Hesse, où se trouvent aujourd'hui ses Personalakten. Incontestablement, Hoffmann a fortement imprégné le travail de la TVK et lui a donné une importance politique que cette petite administration, initialement en charge de la seule conservation des œuvres, ne possédait pas. En effet, son expertise en matière artistique et sa bonne connaissance des enjeux politiques ont fait de la TVK un "pôle de compétence ${ }^{39}$, très sollicité avant 1955 par les Américains (qui ne disposent plus de bureau des restitutions après la dissolution du CCP) et après 1955 par le Bund für äussere Restitution, qui demande à la TVK d'instruire les dossiers de réclamations.

\section{c) Une caractéristique de l'après-guerre : la féminisation du personnel}

19 Le bureau munichois de la TVK est une petite équipe d'une dizaine de permanents, comprenant, outre Hoffmann et Westphal, cinq secrétaires femmes et trois gardiens. La domination numérique des femmes dans l'équipe de la TVK est frappante (annexe 2). Les archives du ministère des Affaires étrangères sont prolixes sur le recrutement des diverses secrétaires, dont les compétences linguistiques sont clairement recherchées ${ }^{40}$. Ainsi lors du recrutement de Maria Krause en mai 1952, il est fait mention de sa maitrise de l'anglais, jugée nécessaire pour la correspondance avec les Américains et l'utilisation des fichiers légués par le CCP. On le voit aussi à propos du recrutement de Maria Nocken (en poste de 1951 à 1954), qui parle français et a été secrétaire de la mission française pour les restitutions au CCP41. Maria Graifenhagen, secrétaire de 1951 à 1954, ajoute à un cursus en histoire de l'art une connaissance de l'anglais. Ces trois secrétaires ont en commun la capacité linguistique à travailler avec les Alliés. La féminisation du personnel administratif observable à la TVK s'inscrit du reste dans des tendances plus générales de l'après-guerre liées à des facteurs tant démographiques que d'expansion des services publics. Notons par ailleurs que les trois gardiens des œuvres et que les trois premières 
secrétaires de la TVK étaient déjà employés par le CCP, ce qui illustre une continuité recherchée entre le personnel des Américains et celui de la TVK. En outre, la TVK fait appel à des salariés temporaires, par exemple pour le travail photographique. Au total, la modestie de la structure au plan des effectifs étonne eu égard à son rôle politique et international.

\section{d) Le dossier des restitutions et la réflexion sur les « biens culturels » en RFA après la guerre}

20 La TVK développe une réflexion sur les biens culturels dont elle a la charge qui, tout en soulignant constamment la très haute valeur artistique et financière des œuvres, s'efforce de tenir l'équilibre entre la nécessité de restituer - notamment vis-à-vis de l'étranger - et la défense des intérêts ouest-allemands (même si cela n'est pas dit tel quel). C'est pourquoi il convient à présent d'entrer dans le travail concret de la TVK, qui sous couvert de missions techniques (comment inventorier et conserver au mieux les œuvres d'art) traite de sujets politiquement sensibles.

\section{e) Le travail d'inventaire}

21 Le travail d'inventaire prime dans le quotidien de la TVK. Dès 1949, une des missions du bureau munichois est d'établir un nouveau fichier non plus par œuvre (comme dans le CCP avec ses property cards), mais par auteur, afin de faciliter les recherches lors des demandes de restitution. À l'inventorisation des œuvres du CCP de Munich s'ajoute celle des œuvres du Collecting Point de Wiesbaden et de la collection de Göring. Ces inventaires nécessitent des compétences en histoire de l'art, au point que le travail est qualifié de « scientifique » par Hoffmann en $1962^{42}$. Celui-ci compare d'ailleurs dans ce texte la TVK à une " institution muséale » en raison de ses missions. Par ailleurs Hoffmann établit des listes minutieuses des œuvres restituées par pays depuis $1945^{43}$. Ce faisant, il cherche incontestablement à prouver la bonne volonté de la RFA en matière de restitutions.

La comparaison de la TVK avec un musée ne va pourtant pas de soi, car l'accessibilité des œuvres conservées à Munich n'est pas acquise au départ. Dans une lettre adressée à Hoffmann le 19 juillet 1949, l'Américain Murray van Wagoner insiste sur le secret destiné à protéger les objets en attente de restitution ${ }^{44}$ : les Allemands n'ont pas le droit de délivrer en l'absence d'autorisation américaine des informations sur les œuvres conservées. Une note ministérielle d'octobre 1953 rappelle encore à Hoffmann que les fonds de la TVK ne sont pas ouverts au public et que l'accès au dépôt et aux archives est interdit à quiconque ne possédant pas une autorisation des Affaires étrangères ${ }^{45}$. Cependant, une évolution voit le jour car la TVK a prêté des œuvres non restituées à des musées : 180 objets ont été envoyés dans 32 expositions, y compris à l'étranger (à Paris, Londres, Amsterdam ou Vienne) (annexe 3) ${ }^{46}$. La TVK a aussi prêté plus durablement des œuvres, parfois moyennant finances, pour décorer des bâtiments officiels du Land de Bavière (à Munich principalement) et de la RFA, tant à Bonn (chancellerie, Bundestag, ministères) qu'à l'étranger (ambassades et consulats) (annexe 4) ${ }^{47}$ : à titre d'exemple, la TVK prête aux ambassades allemandes à Paris et à Londres respectivement un tableau de Bock (Herbstliche Dahlien) en avril 1955 (contre 400 DM) et un tableau de Guillery (Park am Mondsee) entre août 1956 et avril 1960 (contre 400 DM). Enfin, la TVK a vendu au début des années 1960, pour le compte du Bund, environ cinq cents objets dont les propriétaires ne 
s'étaient pas manifestés (sur la base d'un décret du ministère des Affaires étrangères du 11 décembre 1959), pour une somme globale de plus de $90000 \mathrm{DM}^{48}$. Ces prêts et ventes ne semblent pas avoir soulevé de contestations en RFA, sans doute parce qu'à la suite de la TVK, l'opinion publique pense que le travail de restitution est achevé au début des années 1960.

\section{L'émotion suscitée par les déplacements d'œuvres d'art}

23 Il est clair que le contexte est très différent au début des années 1950, quand les restitutions d'œuvres d'art émeuvent l'opinion ouest-allemande. En RFA, l'agitation contre la restitution des biens juifs est menée par des associations unies en 1950 dans le Bundesverband für Loyale Restitution, qui édite une revue entre 1950 et 1954, Die Restitution ${ }^{49}$. Ce lobby réclame un changement dans la législation, exigence relayée dans les Parlements par la CDU, la CSU et le FDP. Par ailleurs, les experts se mobilisent et alertent l'opinion quand des œuvres d'art risquent de quitter l'Allemagne. Le dossier de presse constitué par le CCP regorge de coupures de journaux polémiques évoquant les départs d'œuvres vers l'étranger ${ }^{50}$. C'est parce que les œuvres circulent que les Allemands de l'Ouest prennent conscience de biens culturels à protéger - car potentiellement allemands selon eux (en l'absence d'identification des propriétaires) -, même si cette idée est irrecevable pour les Alliés.

La première émotion avait été suscitée par le départ de 202 tableaux en décembre 1945 pour Washington (vers la National Gallery) sur décision de la Maison Blanche du 26 septembre 1945, officiellement pour les mettre à l'abri (for safe keeping and in trust for the German People. These works will be returned to the museums when conditions in Europe warrant ${ }^{51}$ ). Parmi ces toiles se trouvent des œuvres de Boticelli, Van Eyck, Memling, Dürer, Raphael, Titien, Giorgione, Rembrandt ou Rubens. Les tableaux reviennent en 1948 en Allemagne, après avoir été vus aux États-Unis par des millions de visiteurs. Notons qu'y compris au sein du camp américain, cette décision n'avait pas fait l'unanimité, notamment parmi les Monuments Men, qui avaient signé le Manifeste de Wiesbaden dénonçant cette mainmise sur les œuvres ${ }^{52}$. Certaines œuvres emmenées aux États-Unis à la fin de la guerre par des soldats rentrent encore plus tardivement en RFA, à l'instar en 1952 d'une peinture de Rubens de sainte Catherine (rendue à la Kunsthalle de Düsseldorf), d'une bague en or égyptienne du premier siècle après J.C. (rendue au musée de Berlin) ou du testament politique de Frédéric le Grand de 1752 (restitué aux archives de Prusse) ${ }^{53}$. Ces retours font l'objet d'une cérémonie à la chancellerie à Bonn, qui célèbre la coopération germano-américaine dans le sauvetage des biens culturels en Europe, en présence côté allemand de Wolff von Metternich (qui représente le ministère des Affaires étrangères) et, côté américain, d'Edgar Breitenbach (officier en charge des questions artistiques au sein du haut commissariat américain en Allemagne ${ }^{54}$ ) et d'Ardelia Hall (représentante du ministère des Affaires étrangères des États-Unis) ${ }^{55}$. Ce type de cérémonies alimente dans l'opinion ouest-allemande l'idée que des œuvres d'art appartenant au peuple allemand se trouvent à l'étranger.

Un autre exemple est l'émotion soulevée en 1951 en Bavière à l'occasion du départ pour Salzbourg des œuvres provenant des dépôts nazis situés en Autriche à la fin de la guerre, alors que leurs propriétaires ne sont pas encore identifiés. La question est débattue au 
Landtag à Munich le 9 août 1951, où un député s'émeut « qu'aucun dédommagement ne soit prévu pour le peuple allemand » et demande au gouvernement de Bavière ce qu'il compte entreprendre "pour empêcher la disparition de ces trésors " ${ }^{56}$. La question des restitutions est aussi soulevée au Bundestag le 15 novembre 1951. Les Alliés procèdent néanmoins le 22 février 1952 à l'envoi à Salzbourg des 1900 objets du complexe d'AltAussee, malgré une intense campagne de protestation ouest-allemande. On voit qu'à cette date les restitutions aux pays étrangers sont loin d'aller de soi pour l'opinion du pays. Selon un expert du Comité allemand de restitution, les réclamations autrichiennes seraient infondées du point de vue du droit international. Heydenreich écrit en juillet 1951 au ministère des Affaires étrangères de la RFA pour enjoindre le gouvernement fédéral de clarifier cette question juridique, «indépendamment du fait que ces œuvres seront définitivement perdues pour l'Allemagne ». Quant à Hanfstaengl, il conteste la légalité des réclamations autrichiennes dans une lettre adressée le 10 août 1951 au gouvernement de Bavière ${ }^{57}$. On voit que les restitutions ne sont pas portées par un consensus intérieur en RFA lors de la reconstruction de la société civile : les principales impulsions en matière de restitutions sont en fait venues de l'étranger (Alliés et organisations juives internationales).

\section{Quel bilan des restitutions en 1962 ?}

Le bilan d'activité de la TVK est délicat à établir : nous dépendons ici du rapport établi par Hoffmann en $1962^{58}$. Les restitutions «intérieures»sont distinguées des restitutions « extérieures » dans la convention relative à la fin de l'occupation de l'Allemagne en 1955. Notons que Wolff von Metternich a participé aux négociations en amont de la convention en 1951-1952 $2^{59}$. Par ailleurs, Bernhard Hoffmann a cherché à peser sur les négociations dans un sens favorable à la RFA en rédigeant un mémorandum en 1952. Ce mémorandum (dont le porte-parole officiel est Ludwig Heidenreich du Comité allemand de restitution) réclame le "traitement paritaire des réclamations allemandes" (c'est-à-dire des restitutions d'œuvres à la RFA), un délai limité dans le temps pour le dépôt des réclamations étrangères auprès de la RFA, ainsi que l'exclusion du périmètre des réclamations des biens achetés sur le marché de l'art dans les pays occupés. L'initiative échoue, mais Hoffmann réussit à imposer comme condition pour réclamer un objet d'apporter la preuve qu'il se trouvait dans le pays avant l'occupation allemande (ce point est jugé important pour l'Autriche).

D'après le traité de 1955, les restitutions intérieures se font sur ordre des « autorités de réparation" (Wiedergutsmachungsbehörden), qui ont la compétence de restituer ou d'indemniser les ayants droit pour des biens saisis sur le territoire allemand. Mais selon Corinne Bouchoux, le contexte est plutôt celui d'une "non restitution» des biens confisqués aux juifs ${ }^{60}$, car les autorités du fisc (ministre fédéral des Finances et Oberfinanzdirektionen des Länder) ont défendu les intérêts des États face aux personnes spoliées. Entre 1947 et 1962, 16000 objets ont été restitués à des propriétaires ou ayants droit juifs en Allemagne, ce qui est très peu en comparaison avec le nombre de restitutions vers l'étranger entre ces dates ${ }^{61}$. En matière de restitutions extérieures, le vote le 15 juillet 1957 de la loi fédérale de restitution (Bundesrückerstattungsgesetz, BRüG) permet d'indemniser les propriétaires dans tous les territoires qui ont été occupés en Europe par l'armée allemande quand il est établi que les œuvres ont été transportées sur le territoire de la RFA ou à Berlin-Ouest. Cependant les victimes ont la charge de la 
preuve. De plus, l'Autriche reste en dehors du périmètre de la loi. Enfin, le bloc soviétique est exclu de son champ d'application puisque les pays pouvant réclamer doivent entretenir des relations diplomatiques avec la RFA. Au total, en raison de sa formulation très précise et de la guerre froide, la loi BRüG a eu une portée limitée et n'a pas beaucoup pesé sur le budget de la RFA (les indemnisations se sont élevées à 4 milliards de DM jusqu'à $\left.1971^{62}\right)$.

Néanmoins, une quarantaine de restitutions extérieures ont eu lieu entre mai 1955 et juin 1962 (la liste établie par Hoffmann mentionne neuf restitutions vers la France, une vers les Pays-Bas et trente-quatre vers l'Autriche). Lors de sa dissolution, la TVK transfère le 1 er janvier 1962 quelques 20000 œuvres au Bundesschatzminister de la RFA. Celui-ci prête en 1966 à une centaine de musées ouest-allemands environ 500 objets que les directeurs avaient pu sélectionner au préalable lors d'une exposition au château de Schleissheim près de Munich ${ }^{63}$. Quant aux quelques 19000 objets restants, ils sont conservés dans le dépôt de l'oberfinanzdirektion de Munich. Certains sont propriété de la RFA, d'autres de la RDA, certains encore sont revendiqués par Emma Göring, d'autres enfin n'ont pas de propriétaire identifié. L'optimisme de Hoffmann en 1962, qui pense que le travail de restitution est quasiment achevé (selon lui, il ne resterait que 153 objets en attente), est donc à relativiser : on sait qu'aujourd'hui de nombreuses œuvres soit sont encore cachées (ainsi que le montre la révélation en novembre 2013 de la collection secrète à Munich de Cornelius Gurlitt comprenant plus de 1400 œuvres dont certaines de Picasso, Matisse, Renoir et Otto Dix ${ }^{64}$ ), soit ont été restituées à des pays qui ne les ont pas transmises aux ayants droit (ainsi la France conserve actuellement dans ses musées publics près de 2000 œuvres inscrites au registre des « Musées nationaux récupération » ${ }^{65}$ ), soit font l'objet de transactions commerciales depuis leur réapparition sur le marché de l'art international après la chute du Mur de Berlin et l'effondrement du bloc soviétique ${ }^{66}$.

\section{Conclusion}

L'intérêt d'une micro-histoire de la TVK provient du fait que cette petite administration se situe au cœur de grands enjeux internationaux de l'après-guerre et acquiert rapidement, de par l'expertise de son personnel, une importance permettant à la RFA de participer à la politique de restitution dictée jusqu'en 1955 par les Alliés occidentaux. Le personnel de la TVK, pour une bonne part recruté par les Américains dans le cadre du CCP de Munich, présente un profil antinazi grâce auquel elle peut se présenter comme interlocuteur légitime. Cette administration est assez atypique dans le paysage administratif ouest-allemand du début des années 1950, marqué par la réintégration dans leurs droits des anciens fonctionnaires du Troisième Reich, dont la situation juridique a été clarifiée par la loi du 11 mai 1951 relative au paragraphe 131 de la Loi fondamentale : en effet, dans la plupart des administrations, l'arrivée massive au début des années 1950 des 131er marginalise le personnel antinazi recruté en 1945/46 au plus fort de l'épuration. L'originalité de la TVK est donc d'avoir réussi à maintenir une bonne part de son personnel initial, à contre-courant du retour des « anciens » dans les services publics. Le fait que cette institution ait été créée ex nihilo après la guerre y a certainement contribué. Les conséquences en termes de pratiques sont importantes: la TVK a réussi à se constituer au cours d'une décennie un domaine d'expertise unique, lui permettant de devenir l'instance principale côté ouest-allemand dans le dossier des restitutions et même d'intervenir dans les négociations avec les Alliés, comme lors de la convention mettant 
fin au statut d'occupation. Cette étude de cas montre l'intérêt qu'il y a à partir des personnels pour comprendre le fonctionnement des administrations ouest-allemandes après la guerre, en deçà des évolutions macro-sociales connues. L'orientation principale semble être ici un compromis raisonnable entre les attentes des Alliés et les intérêts ouest-allemands.

\section{ANNEXES}

\section{Annexe 1}

Tableau établi par la TVK récapitulant les œuvres sous tutelle de la Bavière au 4 avril 1951

\begin{tabular}{|c|c|c|c|c|c|c|c|c|}
\hline Eigentümer & Gemälde & Zeichnungen & Drucke & Möbel & Textile & Kunstgewerbe & Plastik & Verschiedenes \\
\hline $\begin{array}{l}\text { Deutscher } \\
\text { Staatsbesitz }\end{array}$ & & & & 26 & 141 & 1 & & 1 \\
\hline Parteibesitz & 454 & 25 & 53 & & 1 & & 2 & 105 \\
\hline Reichsleitung & 30 & 1 & & & 5 & & & 1 \\
\hline $\begin{array}{l}\text { Parteiforum } \\
\text { Berchstesgaden }\end{array}$ & 88 & 16 & 33 & & & & 2 & \\
\hline $\begin{array}{l}\text { Ankäufe der } \\
\text { Reichskanzlei }\end{array}$ & 382 & 17 & 2 & 6 & 1 & 7 & 1 & 5 \\
\hline $\begin{array}{l}\text { Aussee, } \\
\text { unbekannte } \\
\text { Bestimmung }\end{array}$ & 27 & 9 & 9 & 13 & 141 & 51 & 3 & 119 \\
\hline $\begin{array}{l}\text { Aussee, Linz- } \\
\text { Sammlung }\end{array}$ & 1460 & 127 & 42 & 1 & 5 & 65 & 39 & 36 \\
\hline $\begin{array}{l}\text { Linz, nicht } \\
\text { österreichischen } \\
\text { Depots }\end{array}$ & 139 & 3 & & & & & 4 & \\
\hline $\begin{array}{l}\text { Aussee, Bormann } \\
\text { Sammlung und } \\
\text { Verwaltung } \\
\text { Obersalzberg }\end{array}$ & 499 & 93 & 3 & & 13 & 17 & 18 & 1 \\
\hline
\end{tabular}




\begin{tabular}{|c|c|c|c|c|c|c|c|c|}
\hline $\begin{array}{l}\text { Bormann, } \\
\text { deutsche Depots }\end{array}$ & 12 & 598 & & & & & & \\
\hline $\begin{array}{lr}\text { Aussee, } & \text { für } \\
\text { Schloss } & \text { Posen } \\
\text { bestimmt } & \end{array}$ & 229 & 18 & 1 & & & & & \\
\hline $\begin{array}{l}\text { Posen, deutsches } \\
\text { Depot }\end{array}$ & 3 & & & & & & & \\
\hline $\begin{array}{l}\text { Aussee, } \\
\text { Himmler, } \\
\text { beschlagnahmter } \\
\text { Berliner Gut }\end{array}$ & 57 & & & & & & & \\
\hline $\begin{array}{l}\text { Aussee, Posse } \\
\text { Stiftung Linz }\end{array}$ & 26 & 132 & 8 & 29 & 1 & 82 & 24 & 11 \\
\hline $\begin{array}{l}\text { Posse, nicht } \\
\text { österreichische } \\
\text { Depots }\end{array}$ & & & & & & 11 & & \\
\hline $\begin{array}{l}\text { Aussee, vielleicht } \\
\text { für Linz } \\
\text { bestimmt }\end{array}$ & 44 & 17 & 35 & 8 & & & 10 & 63 \\
\hline $\begin{array}{l}\text { Wehrmacht, } \\
\text { Kriegsmarine }\end{array}$ & 8 & & 12 & 22 & & 8 & & \\
\hline $\begin{array}{l}\text { Hohenfurth, } \\
\text { Hitler Sammlung }\end{array}$ & & & & 3 & & & & \\
\hline $\begin{array}{l}\text { Passau, Ober- } \\
\text { Bürgermeister }\end{array}$ & 21 & 17 & 50 & & & & & \\
\hline $\begin{array}{l}\text { General-Baurat } \\
\text { München }\end{array}$ & 37 & & & 39 & 13 & 1 & & 3 \\
\hline Alte Pinakothek & & & & & 1 & & & \\
\hline $\begin{array}{l}\text { Kameradschaft } \\
\text { der Künstler }\end{array}$ & 77 & 78 & 10 & & 1 & 1 & & \\
\hline Maximilianeum & 8 & & & & & & & \\
\hline $\begin{array}{l}\text { Sven } \\
\text { Institut }\end{array}$ & & & & & & & & 81 \\
\hline $\begin{array}{l}\text { Haus } \quad \text { der } \\
\text { Technik }\end{array}$ & & & & & & & 8 & 1 \\
\hline
\end{tabular}




\begin{tabular}{|c|c|c|c|c|c|c|c|c|}
\hline $\begin{array}{lr}\text { Haus } & \text { für } \\
\text { deutsches Recht }\end{array}$ & 3 & 2 & & & & & & \\
\hline Göring & 323 & 12 & 39 & 188 & 233 & 425 & 184 & 301 \\
\hline Goebbels & 1 & & & & & & & \\
\hline Frick & 6 & & 13 & & & 5 & 5 & 3 \\
\hline Rudolf Hess & & 9 & 5 & & & & & 1 \\
\hline Adolf Wagner & & & & & 1 & & & \\
\hline Streicher & 7 & & & & & & & 3 \\
\hline Christian Weber & 21 & & 9 & 2 & 8 & 109 & 28 & 2 \\
\hline Robert Ley & 4 & & & & & & & \\
\hline Ritter von Epp & 74 & 3 & 6 & & & 16 & 2 & 1 \\
\hline $\begin{array}{ll}\text { Baldur } & \text { von } \\
\text { Schirach } & \end{array}$ & 9 & & 10 & 22 & & 5 & 8 & 16 \\
\hline $\begin{array}{l}\text { Heinrich } \\
\text { Hoffmann }\end{array}$ & 135 & 9 & 8 & 6 & 17 & 68 & 19 & 40 \\
\hline Dr Frank & 19 & 5 & 45 & 9 & 2 & 8 & 6 & 3 \\
\hline Jüdisch & 1 & & & & & & & \\
\hline Deutscher Besitz & 56 & 13 & 48 & 82 & 3 & 17 & 18 & 50 \\
\hline $\begin{array}{l}\text { Deutscher } \\
\text { bekannter } \\
\text { Privatbesitz }\end{array}$ & 38 & 12 & 23 & 3 & 3 & 25 & 13 & 87 \\
\hline $\begin{array}{l}\text { Deutscher } \\
\text { unbekannter } \\
\text { Privatbesitz }\end{array}$ & 143 & 7 & 16 & 2 & 14 & 31 & 6 & 23 \\
\hline $\begin{array}{l}\text { Summe : } \\
9528 \\
\text { Objekte }\end{array}$ & 4441 & 1223 & 480 & 461 & 604 & 953 & 400 & 966 \\
\hline
\end{tabular}

\section{Annexe 2}

Liste du personnel permanent de la TVK à Munich par date d'entrée en fonction

(source : AA, B 95, liasse 988) 
Dr Bernhard Hoffmann (1951-1962)

Dr Dorothea Westphal (1951-1956)

Maria Greifenhagen (1951-1958)

Marie Nocken (1951-1954)

Eva Netwig (1951-1953)

Friedrich Riedel (1951-1952)

Gertrud Hubala (1952-1953)

Elga Böhm (1952)

Johann Konrad (1952)

Max Rauschenberger (1952-1955)

Ignaz Wasmaier (1952-1956)

Erika Fruth (1953-1955)

Dr Barabara Reuter (1954-1956)

Josef Drexl (1955)

Margarete Holpert (1955-1957)

Luise Beissbarth (1956-1962)

Klara Roselius (1956-1962)

Gertrud Schrewe (1957-1958)

Ingrid Schrembs (1960)

\section{Annexe 3}

Tableau établi par la TVK des œuvres sous tutelle fédérale prêtées à des expositions artistiques entre 1952 et 1962

\begin{tabular}{|l|l|l|}
\hline Lieux des expositions & $\begin{array}{l}\text { Titres (et dates) des expositions par ordre } \\
\text { chronologique }\end{array}$ & $\begin{array}{l}\text { Nombre } \\
\text { d'œuvres } \\
\text { prêtées }\end{array}$ \\
\hline München (Haus der Kunst) & $\begin{array}{l}\text { Meisterwerke der Französischen Malerei von } \\
\text { Poussin bis Ingres (1952/53) }\end{array}$ & 5 \\
\hline Erding & $\begin{array}{l}\text { Ausstellung anlässlich der 725-Jahrfeier der } \\
\text { Stadt (1953) }\end{array}$ & 2 \\
\hline Salzburg (Residenz-Galerie) & Ferdinand Georg Waldmüller (1943) & 29 \\
\hline $\begin{array}{l}\text { Rotterdam (Museum } \\
\text { Boymans) }\end{array}$ & Olieverfschetsen van Rubens (1953/54) & 1 \\
\hline Wolfsburg (Goetheschule) & Wilhelm Leibl & 1 \\
\hline
\end{tabular}




\begin{tabular}{|c|c|c|}
\hline Salzburg (Residenz-Galerie) & Makart und seine Zeit (1954) & 16 \\
\hline $\begin{array}{l}\text { Hannover (Niedersächsische } \\
\text { Landesgalerie) }\end{array}$ & Wilhelm Leibl Ausstellung (1954) & 1 \\
\hline $\begin{array}{l}\text { München (Technische } \\
\text { Hochschule, Bibliothek) }\end{array}$ & Fünf Jahrhunderte Architektur im Bild (1954) & 13 \\
\hline $\begin{array}{l}\text { Düsseldorf } \\
\text { (Ausstellungsgelände) }\end{array}$ & Internationale Jagdausstellung (1954) & 2 \\
\hline $\begin{array}{lr}\text { Pforsheim (Kunst- } & \text { und } \\
\text { Kunstgewerbeverein } & \text { im } \\
\text { Industriehaus) } & \end{array}$ & Reuchlin und die Kunst seiner Zeit (1955) & 9 \\
\hline Berlin (Museum Dahlem) & $\begin{array}{l}\text { Adolph von Menzel aus Anlass seines } 50 . \\
\text { Todestages (1955) }\end{array}$ & 19 \\
\hline Wien (Albertina) & $\begin{array}{l}\text { Rudolf von Alt 1812-1905 (zum 50. Todesjahr) } \\
\text { (1955) }\end{array}$ & 5 \\
\hline Wolfsburg (Mittelschule) & $\begin{array}{l}\text { Deutsche Malerei seit Caspar David Friedrich } \\
(1956)\end{array}$ & 6 \\
\hline Recklinghausen (Kunsthalle) & Beginn und Reife (1956) & 2 \\
\hline Kiel (Kunsthalle) & $\begin{array}{l}\text { Meisterwerke Deutscher und Österreichischer } \\
\text { Malerei 1800-1900 (1956) }\end{array}$ & 11 \\
\hline $\begin{array}{lr}\text { Amsterdam } & \text { (Rijksmuseum), } \\
\text { Rotterdam } & \text { (Museum } \\
\text { Boymans) } & \end{array}$ & Rembrandt (1956) & 1 \\
\hline $\begin{array}{l}\text { München (Staatliche } \\
\text { Graphische Sammlung) }\end{array}$ & Deutsche Zeichnungne 1400-1900 (1956) & 1 \\
\hline Wien (Neue Hofburg) & J.B. Fischer von Erlach (1957) & 1 \\
\hline Recklinghausen (Kunsthalle) & Verkannte Kunst (1957) & 8 \\
\hline Bamberg (Neue Residenz) & $\begin{array}{l}\text { Aus Bambergs grosser Geschichte (zum } 950 . \\
\text { Gründungsjubiläums des Bistums Bamberg } \\
\text { (1957) }\end{array}$ & 1 \\
\hline $\begin{array}{ll}\text { Straubing } & \text { (Grosser } \\
\text { Rathaussaal) } & \end{array}$ & Münchner Malerei des 19. Jahrhunderts (1958) & 5 \\
\hline $\begin{array}{l}\text { Baden-Baden } \quad \text { (Staatliche } \\
\text { Kunsthalle) }\end{array}$ & Aus der Zeit um 1900 (1958) & 1 \\
\hline München (Haus der Kunst) & $\begin{array}{l}\text { München 1869-1958. Aufbruch zur modernen } \\
\text { Kunst (1958) }\end{array}$ & 16 \\
\hline
\end{tabular}




\begin{tabular}{|c|c|c|}
\hline München (Städtische Galerie) & 400 Jahre Münchner Malerei (1958) & 4 \\
\hline München (Städtische Galerie) & $\begin{array}{l}\text { Carl Spitzweg (zur 150. Wiederkehr seines } \\
\text { Geburtstages) (1958) }\end{array}$ & 1 \\
\hline London (Tate Gallery) & $\begin{array}{l}\text { The Romantic Movement (5th Exhibition to } \\
\text { celebrate the 10th Anniversary of the Council of } \\
\text { Europe) (1959) }\end{array}$ & 1 \\
\hline Recklinghausen (Kunsthalle) & Die Handschrift des Künstlers (1959) & 11 \\
\hline $\begin{array}{l}\text { Karlsruhe } \quad \text { (Staatliche } \\
\text { Kunsthalle) }\end{array}$ & Hans Baldung Grien (1959) & 2 \\
\hline München (Stadtmuseum) & $\begin{array}{l}\text { Bayerische Frömmigkeit. } 1400 \quad \text { Jahre } \\
\text { Christliches Bayern (Ausstellung anlässlich des } \\
\text { Eucharistischen Weltkongresses München 1960) } \\
(1960)\end{array}$ & 1 \\
\hline $\begin{array}{l}\text { Paris (Musée National d'Art } \\
\text { moderne) }\end{array}$ & Les sources du XXe siècle (1960/61) & 3 \\
\hline $\begin{array}{l}\text { Berlin } \\
\text { Charlottenburg) }\end{array}$ & $\begin{array}{l}\text { Meisterwerke aus den Schlössern Friedrichs des } \\
\text { Grossen (zum 250. Geburtstages Friedrich des } \\
\text { Grossen) (1962) }\end{array}$ & 5 \\
\hline München (Städtische Galerie) & Gedächtnisausstellung Franz Simm (date ?) & 2 \\
\hline
\end{tabular}

(source : BArch, B 323 / 762, annexe 16, p. 135-146)

\section{Annexe 4}

Tableau établi par la TVK des objets prêtés pour décorer des bâtiments officiels de la RFA entre 1952 et 1962 (source : BArch, B 323 / 762, annexe 15, p. 94-134)

\begin{tabular}{|l|l|l|}
\hline Villes et institutions & $\begin{array}{l}\text { Objets } \\
\text { prêtés }\end{array}$ & $\begin{array}{l}\text { Date du prêt / } \\
\text { durée du prêt }\end{array}$ \\
\hline Bonn, Freistaat Bayern Bevollmächtigte beim Bund & 6 & 1950 \\
\hline Bayreuth, Verwaltungsgericht & 1 & $1950-1953$ \\
\hline Berlin, ehemalige Staatliche Museen Berlin-Dahlem & 1 & 1952 \\
\hline Berlin, ehemalige Staatliche Museen Nationalgalerie & 1 & 1961 \\
\hline Bonn, Auswärtiges Amt (Zentrale) & 32 & 1956 \\
\hline
\end{tabular}




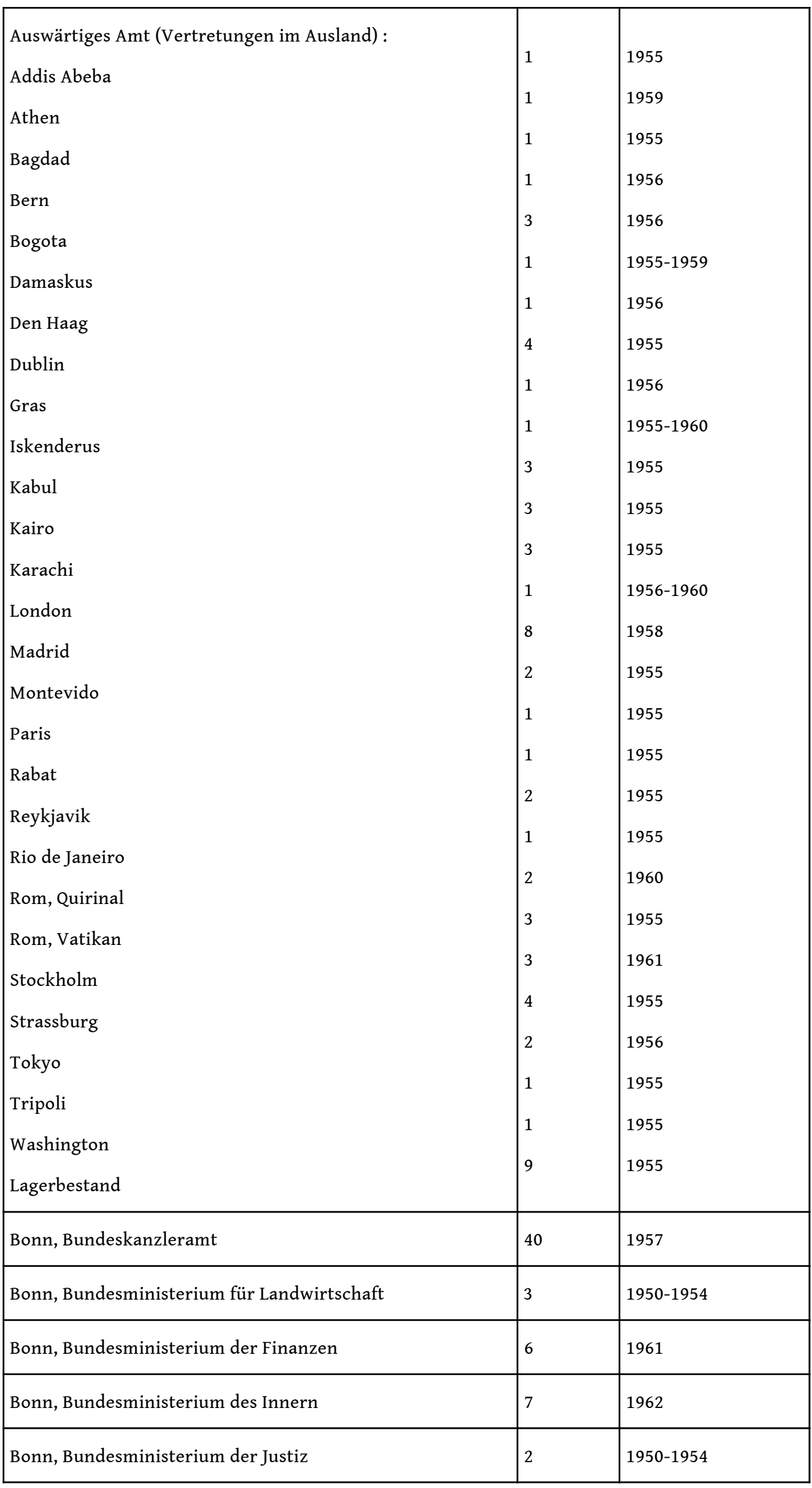




\begin{tabular}{|c|c|c|}
\hline $\begin{array}{l}\text { Bonn, Bundesministerium für Wohnungswesen, Städtebau } \\
\text { und Raumordnung }\end{array}$ & 5 & 1962 \\
\hline Bonn, Bundesschatzministerium & 23 & 1962 \\
\hline Bonn, Deutscher Bundestag & 38 & 1957 \\
\hline Herrsching, Tuberkulose-Krankenhaus & 27 & $1948-1953$ \\
\hline $\begin{array}{l}\text { Hohenaschau, Schloss Ferienheim des Sozialwerkes der } \\
\text { Bundesfinanzverwaltung e.V. }\end{array}$ & 1 & 1962 \\
\hline Köln, Wallraf-Richartz-Museum & 2 & 1961 \\
\hline München, Amerika-Institut der Universität & 1 & 1949-1957 \\
\hline München, Amerikanisches Generalkonsulat & 20 & $1946-1954$ \\
\hline $\begin{array}{l}\text { München, Bayerisches Staatsministerium für Arbeit und } \\
\text { Soziale Fürsorge }\end{array}$ & 3 & $1949-1954$ \\
\hline München, Bayerische Versuchsanstalt & 1 & 1950-1954 \\
\hline $\begin{array}{l}\text { München, Bayerisches Staatsministerium für Unterricht } \\
\text { und Kultus }\end{array}$ & 4 & $1949-1954$ \\
\hline München, Bayerische Landesanstalt für Aufbaufinanzierung & 2 & 1951-1954 \\
\hline München, Bayerische Landesimpfanstalt & 3 & 1949-1954 \\
\hline München, Bayerische Staatsbank & 4 & 1951-1954 \\
\hline München, Bayerische Staatsbibliothek & 12 & 1951-1954 \\
\hline München, Bayerische Staatsgemäldesammlungen & 26 & 1951 \\
\hline München, Bayerische Staatskanzlei & 1 & 1950-1952 \\
\hline München, Bayerischer Landtag & 14 & 1950-1954 \\
\hline München, Bayerisches Nationalmuseum & 2 & 1952 \\
\hline München, Bayerisches Staatsministerium der Finanzen & 63 & $1948-1954$ \\
\hline München, Bayerisches Staatsministerium des Innern & 2 & 1951-1954 \\
\hline $\begin{array}{l}\text { München, Bayerisches } \quad \text { Staatsministerium für } \\
\text { Verkehrsangelegenheiten }\end{array}$ & 10 & $1949-1952$ \\
\hline München, Bayerischer Verwaltungsgerichtshof & 5 & 1949-1953 \\
\hline München, Blessed Sacred Chapel & 2 & $1950-1955$ \\
\hline
\end{tabular}




\begin{tabular}{|c|c|c|}
\hline München, Zentralinstitut für Kunstgeschichte & 1 & $1953-1954$ \\
\hline München, Finanzgericht & 2 & $1952-1954$ \\
\hline München, Inspektor H. Haidacher & 2 & $1950-1955$ \\
\hline München, Prof. Heydenreich & 4 & $1949-1953$ \\
\hline $\begin{array}{l}\text { München, Haus der Kunst, Offiziers- und Zivilclub und } \\
\text { Messe }\end{array}$ & 43 & $1947-1955$ \\
\hline München, Heizkraft A.-G. & 1 & $1947-1960$ \\
\hline München, Institut fûr Pharmazie der Universität & 3 & $1949-1954$ \\
\hline München, Klenze-Oberrealschule & 1 & $1950-1954$ \\
\hline München, Kreis-Archiv & 1 & $1951-1954$ \\
\hline München, Landesarbeitsgericht & 1 & 1949-1953 \\
\hline München, Landesversorgungsamt & 15 & $1948-1954$ \\
\hline München, Langerichtspräsident II & 2 & $1950-1954$ \\
\hline München Mac Cormac & 7 & $1946-1954$ \\
\hline München, Medizinische Tierklinik & 1 & $1951-1954$ \\
\hline München, Oberlandesgericht & 12 & $1950-1954$ \\
\hline $\begin{array}{l}\text { München, Seminar für Ostasiatische Kulturwissenschaft der } \\
\text { Universität }\end{array}$ & 1 & 1948 \\
\hline München, Deutsches Patentamt & 3 & 1950-1959 \\
\hline München, Rotkreuzkrankenhaus I & 3 & $1952-1953$ \\
\hline München, Sozialgericht & 2 & $1950-1954$ \\
\hline München, Staatliche Graphische Sammlung & 28 & 1952 \\
\hline München, Staatliche Münzsammlung & 35 & 1949 \\
\hline München, Bayerische Staatshauptkasse & 2 & $1950-1954$ \\
\hline München, Wiedergutmachungskammer & 1 & $1949-1954$ \\
\hline München, Dr Ch. D. Winning & 2 & 1949-1952 \\
\hline München, Zentralinstitut für Kunstgeschichte & 1 & 1951-1953 \\
\hline Passau, Oberhausmuseum & 1 & 1956 \\
\hline
\end{tabular}




\begin{tabular}{|l|l|l|}
\hline Pfaffenhofen, Landwirtschaftsamt & 5 & $1951-1953$ \\
\hline Schlüchtern, Kulturgesellschaft e.V. & 12 & $1952-1960$ \\
\hline
\end{tabular}

\section{NOTES}

1. On peut citer par ordre chronologique: Constantin Goschler/Jürgen Lillteicher (dir.), « Arisierung » und Restitution. Die Rückerstattung jüdischen Eigentums in Deutschland und Österreich nach 1945 und 1989, Göttingen: Wallstein, 2002 ; Constantin Goschler/Philipp Ther (dir.), Raub und Restitution. « Arisierung » und Rückerstattung des jüdischen Eigentums in Europa, Frankfurt am Main : Fischer Taschenbuch Verlag, 2003 ; Julius Schoeps/Anna-Dorothea Ludewig (dir.), Eine Debatte ohne Ende? Raubkunst und Restitution im deutschsprachigen Raum, Berlin: Verlag für BerlinBrandenburg, 2007 ; Dan Diner/Gotthart Wunberg, Restitution and Memory. Material Restoration in Europe, New York/Oxford: Berghahn Books, 2007 ; Raub und Restitution. Kulturgut aus jüdischem Besitz von 1933 bis heute (Ausstellung 2008), Göttingen/Berlin/Frankfurt am Main : Wallstein/ Stiftung Jüdischen Museen Berlin/Jüdische Museen, 2008.

2. Sur la politique ouest-allemande de restitution: Constantin Goschler, «Die Politik der Rückerstattung in Westdeutschland ", in: Constantin Goschler/Jürgen Lillteicher (dir.), «Arisierung» und Restitution, op. cit., p. 99-126; Jürgen Lillteicher, "Westdeutschland und die Restitution jüdischen Eigentums in Europa (1947-1957) », in: Constantin Goschler/Philipp Ther (dir.), Raub und Restitution, op. cit., p. 92-107; Jürgen Lillteicher, Raub, Recht und Restitution: die Rückerstattung jüdischen Eigentums in der frühen Bundesrepublik Deutschland, Göttingen : Wallstein, 2007.

3. Sur la TVK, Anja Heuss, « Die Restitution von Kulturgütern in Deutschland 1945-1966 », in : Eine Debatte ohne Ende ?..., op. cit., p. 15-34. Anja Heuss a par ailleurs écrit Kunst und Kulturgutraub : eine vergleichende Studie zur Besatzungspolitik der Nationalsozialisten in Frankreich und in der Sowjetunion, Heidelberg : Winter, 2000.

4. Corinne Bouchoux, "Si les tableaux pouvaient parler...». Le traitement politique et médiatique des retours d'œuvres d'art pillées et spoliées par les nazis (France 1945-2008), Rennes: PUR, 2013. Sur la TVK : p. 243-246.

5. Les fonds de la TVK sont d'une part ceux du bureau de Munich, conservés aux archives fédérales de Coblence (BArch, B 323), et d'autre part ceux du ministère des Affaires étrangères à Berlin (AA, B 95 Referat 605/IV 6). Notons que les dossiers personnels (Personalakten) des employés de la TVK ne sont pas encore accessibles.

6. Eckert Conze (et alii), Das Amt und die Vergangenheit. Deutsche Diplomaten im Dritten Reich und in der Bundesrepublik, München: Blessing, 2010; Martin Sabrow, Das Auswärtige Amt und seine umstrittene Vergangenheit : eine deutsche Debatte, Frankfurt am Main : Fischer Taschenbuch Verlag, 2014.

7. Parmi les hauts fonctionnaires du ministère des Affaires étrangères en 1954, 23\% étaient déjà dans ce ministère sous le régime nazi (soit environ 200 individus) et $34 \%$ étaient d'anciens membres du NSDAP (soit 325 individus). Chiffres donnés par Eckart Conze, Das Auswärtige Amt vom Kaiserreich bis zur Gegenwart, München : Beck, 2013, p. 102 sq.

8. Dominik Rigoll, Staatsschutz in Westdeutschland. Von der Entnazifizierung zur Extremistenabwehr, Göttingen : Wallstein, 2013.

9. Cet historique s'appuie sur Jürgen Lillteicher, « Westdeutschland und die Restitution jüdischen Eigentums in Europa », art. cit.

10. Celle-ci est retracée dans Robert M. Edsel, Monuments Men. Rose Valland et le commando d'experts à la recherche du plus grand trésor nazi, Paris : Editions J.-C. Lattès, 2010. 
11. Craigh Hugh Smyth (1915-2006) a été élève à Princeton de l'historien et théoricien d'art d'origine allemande Erwin Panovsky (1892-1968). Celui-ci a émigré en 1934 aux États-Unis suite à sa révocation en 1933 de l'Université de Hambourg par les nazis à cause de son origine juive.

12. Iris Lauterbach, "Der Central Art Collecting Point in München », in : Raub und Restitution. Kulturgut aus jüdischem Besitz..., op. cit., p. 195-201.

13. Chiffre donné par Anja Heuss, art. cit.

14. Cette biographie s'appuie sur Jan May, «Eberhard Hanfstaengl als deutscher Kommissar auf der Biennale von Venedig, 1934-1936», in : Jörn Brabowski/Petra Winter (dir.), Zwischen Politik und Kunst. Die staatlichen Museen zu Berlin in der Zeit des Nationalsozialismus, Köln : Böhlau, 2013, p. $185-196$.

15. BArch, NS 26 / 2500.

16. Sur le Comité allemand de restitution, BArch, B 323 / 326.

17. Eckart Conze, Das Auswärtige Amt vom Kaiserreich bis zur Gegenwart, op. cit.

18. BArch, B 323 / 326

19. Id.

20. Id.

21. Iris Lauterbach (dir.), Kunstgeschichte in München 1947. Institutionen und Personen im Wiederaufbau, München : Zentralinstitut für Kunstgeschichte, 2010.

22. BArch, Hauptarchiv NSDAP Beauftragter des Führers für die Überwachung der gesamten geistigen und weltanschaulichen Schulung und Erziehung der NSDAP, NS 15 / 131, p. 56 et NS 15 / 31, p. 17.

23. Rose Valland, Le Front de l'art. Défense des collections françaises 1939-1945 (1961), Paris : Réunion des Musées nationaux, 1997, p. 33. Le rôle de Metternich est présenté par Corinne Bouchoux, op. cit., p. 41.

24. Sur les saisies opérées en France par l'ERR, voir Hector Feliciano, Le Musée disparu. Enquête sur le pillage des cuvres d'art en France par les nazis, Paris : Austral, 1995, p. 117-130. Pour une analyse de la concurrence s'exerçant entre les différents acteurs allemands impliqués dans les spoliations en Europe occupée et ses conséquences en termes de radicalisation du processus, voir Jonathan Petropoulos, "The Polycratic Nature of Art Looting : the Dynamic Balance of the Third Reich », in : Gerald D. Feldman/Wolfgang Seibel (dir.), Networks of Nazi Persecution, Oxford/New York: Berghahn Book, 2005, p. 103-117.

25. Rose Valland, op. cit., p. 226.

26. BArch, R 2 / 2935, Band 1 : Young Plan Stellungnahmen und Entschließungen.

27. BArch, B 109 / 630, p. 170.

28. «[...] However, without awaiting the final establishment of contractual or other arrangements with respect to the restitution of works of art I would at this time approve the transfer to the Federal Republic of the custody of certain cultural properties now in possessions of HICOG as well as cultural properties held in temporary trust by the Land Hesse and by the Land Bavaria (all these properties are presently located at the Central Collecting Points at Wiesbaden and Munich). I would therefore welcome the immediate establishment of an official agency by the Federal Government for this purpose. » BArch B 323 / 762.

29. Chiffre donné par Anja Heuss, art. cit.

30. AA, B $95, n^{\circ} 988$.

31. BArch, B $323 / 523$.

32. Von Tieschowitz est cité dans les mémoires de Rose Valland, op. cit., p. 35.

33. BArch, B 323 / 762 : Tätigkeitsbericht der TVK.

34. AA, B $95, \mathrm{n}^{\circ} 988$.

35. Sa lettre de mission date du 25 octobre 1952. BArch, B 323 / 523.

36. AA, B 95, $\mathrm{n}^{\circ} 988$.

37. AA, B 95, n987a.

38. AA, B $95, n^{\circ} 988$.

39. L'expression est d'Anja Heuss, art. cit. 
40. AA, B $95, n^{\circ} 988$.

41. Une Commission de récupération artistique a été créée en France le 24 novembre 1944. Elle est dirigée par Albert Henraux et a des représentants au CCP de Munich.

42. BArch, B 323 / 762 .

43. BArch, B 323 / 416 : Verzeichnis der Restitutionen 1945-1962, mit einem Vorwort von Bernhard Hoffmann.

44. BArch, B $323 / 325$

45. AA, B 95, n987a.

46. Annexe 16 du Tätigkeitsbericht de 1962 (12 p.). BArch, B 323 / 762.

47. Annexe 15 du Tätigkeitsbericht de 1962 (41 p.). BArch, B 323 / 762.

48. Chiffre donné par Bernhard Hoffmann, BArch B 323 / 762.

49. Constantin Goschler, "Die Politik der Rückerstattung in Westdeutschland », art. cit., p. 110. Les numéros de la revue sont consultables dans BArch, B 323 / 555 et 556.

50. BArch, B 323 / 553.

51. Note du War Department des États-Unis du 6 décembre 1945. BArch, B 323 / 553.

52. Lynn Nicholas, Le Pillage de l'Europe. Les œuvres d'art volées par les nazis, Paris : Le Seuil, 1995, p. 441.

53. BArch, B 323 / 325.

54. Edgar Breitenbach (1903-1977), officier Monuments Fine Arts and Archives, s'est distingué à la fin de la Seconde Guerre mondiale en retrouvant (en se déguisant) des œuvres d'art de la collection de Göring près de Berchtesgaden (anecdote relatée par Lynn Nicholas, op. cit., p. 489). Il succède à Craigh Hugh Smyth comme directeurs du CCP.

55. Des photos de cette cérémonie sont conservées dans BArch, B 323 / 349.

56. BArch, B $323 / 325$.

57. BArch, B 323 / 325.

58. BArch Koblenz, B 323 / 762.

59. Anja Heuss, art. cit. Cet auteur cite dans la note 16 les protocoles secrets des négociations conservées sous la cote BArch B 323 / 512.

60. Corinne Bouchoux, op. cit., p. 244.

61. Chiffre donné par Bernhard Hoffmann, BArch B 323 / 762.

62. Chiffre donné par Jürgen Lillteicher, « Westdeutschland und die Restitution... », art. cit.

63. Les objets prêtés aux musées sont étiquetés "Dauerleihgabe der Bundesrepublik Deutschland» sans que figure une autre information sur leur provenance.

64. Le père de Cornelius Gurlitt, Hildebrand Gurlitt était en 1938 un des quatre marchands installés dans le château de Schönhausen près de Berlin pour vendre des œuvres prises par les nazis dans les collections allemandes sous prétexte qu'elles étaient « dégénérées ». En 1943, il est chargé à Paris de rechercher des objets pour le Führermuseum de Linz et trafique avec l'ERR. Voir l'article du Monde du 5 novembre 2013.

65. En France, le sujet connaît une actualité historiographique et politique, comme le montre le colloque organisé en janvier 2014 au Sénat. Se pose aussi l'avenir de la Commission d'indemnisation des victimes de spoliations créée en 1999. Voir les articles du Monde du 15 mars 2014 et du 26 avril 2014.

66. Sur la politique de restitution en Allemagne après 1989, voir Jan Philipp Spannuth, Rückerstattung Ost. Der Umgang der DDR mit dem "arisierten» Eigentum der Juden und die Rückerstattung im wiedervereinigten Deutschland, Essen : Klartext, 2007. 


\section{AUTEUR}

\section{MARIE-BÉNÉDICTE VINCENT}

(École normale supérieure, Paris) 